\title{
Rectal Carcinoma: Multi-Modality Approach in Curative Local Treatment of Early Rectal Carcinoma
}

\author{
S. H. Kho' ${ }^{1}$ S. P. Govilkar' ${ }^{1}$ A. S. Myint ${ }^{2}$ and M. J. Hershman ${ }^{1}$ \\ ${ }^{1}$ Mid Staffordshire NHS Foundation Trust, Stafford; \\ ${ }^{2}$ Clatterbridge Centre for Oncology NHS Foundation Trust, Wirral; \\ UK
}

\section{Introduction}

Rectal carcinoma is currently the fifth most common cancer in the United Kingdom, accounting for approximately 5800 deaths in the UK and 700,000 deaths worldwide annually (UK Cancer Research). The UK Co-ordinating Committee on cancer research defines rectal cancer as any tumour within $15 \mathrm{~cm}$ of the anal verge on rigid sigmoidoscopy. The implementation of bowel screening programme has led to the identification of increasing numbers of early rectal cancer. An increasing elderly population associated with multiple co-morbidities has highlighted the importance of early diagnosis and local treatment options. It remains the leading cause of deaths in the over 75 year's age group.

Early rectal cancer is defined as invasive adenocarcinoma spreading into the submucosa or muscularis propria; T1 or T2 tumours in the tumour node metastasis (TNM) classification (Sobin \& Wittekind, 2002) or Dukes' A in the Dukes' staging. These tumours have a smaller chance to metastasize to local lymph nodes compared to those invading deeper than the muscularis due to the scarce lymphatic system within colorectal mucosa (Day et al 2003).

\section{Epidemiology}

Colorectal cancer is the third most common cancer worldwide and the most common gastrointestinal malignancy in Western countries. From these, almost 30\% arise in the rectum. The incidence of rectal cancer is higher in men (57.9\%) when compared to women (42.1\%), with women also showing an improved survival compared to men, $51.0 \%$ to $48.5 \%$ at 5 years. There has been a steady improvement in the mortality of rectal cancer but 5 year survival in Europe still falls short of American rates. Data collected from the 9 areas in USA over a 4 year period showed 5 year survival rates of 59-66\% (Jeffreys et al., 2006; Sant et al., 2003).

\section{Screening}

A population-based national screening programme was initiated in 2006 based on results of a pilot study of faecal occult blood testing (FOBT) in the UK. A number of countries have 
recommended and now implemented FOBT into their health schemes. In the USA, the American College of Gastroenterology guidelines published in 1997 have stated asymptomatic individuals above the age of 50 years should have a FOBT +/- flexible sigmoidoscopy every 5 years, a double-contrast barium enema or colonoscopy every 10 years.

Colorectal cancer screening guidelines in high risk individuals are based on case-control studies comparing the incidence and the stage of the disease screened and control groups. About $10 \%$ of colorectal cancers run in family due to genetic predispositions (Lynch syndromes). All current evidence predicts that surveillance will improve disease specific survival in these patients. It has been established that screening the average risk population for colorectal cancer reduces cancer specific mortality by $15 \%$ with the FOBT and by $50-80 \%$ post flexible sigmoidoscopy (Rex, 2004; Sant et al., 2003). The international agreement and introduction of the FOBT will improve the prognosis of rectal cancer by improved early diagnosis. Further indirect benefits will also be seen due to increase endoscopic services and quality of endoscopic examinations.

However the colorectal cancer screening programme with FOBT has limitations due to its inability to detect adenomas. The future will see a change from guaiac testing to the use of computed tomography scanning, flexible sigmoidoscopy and faecal DNA testing for selecting patients that need further colonoscopy and polypectomy (Rex, 2000).

\section{Investigations}

Before a management strategy is determined, preoperative imaging is essential in order to determine the stage of the tumour and, therefore, prognostic factors in a patient.

Endorectal ultrasound (ERUS) is a diagnostic technique that allows the stage of both tumour invasion and lymph node metastatic involvement to be determined. Not only it is safe,it also plays a significant role in deciding the most adequate surgical strategy in patients with rectal carcinoma (Bhutani, 2009; Siddiqui et al., 2006). This diagnostic procedure has been used successfully in clinical practice since 1985 as a tool to stage rectal cancer and is most widely used in the United Kingdom.

In order to perform ERUS, the rectum must be empty to ensure that there is no distortion of images due to the presence of faecal matter. Laxative enemas are sufficient for rectal lesions and a preparation is required for colonic lesions. Pre-examination sigmoidoscopy is performed to ensure the lumen is free of debris. ERUS is a well-tolerated procedure and usually does not require sedation.

Carcinomas are hypoechoic, and the stage is determined by the scale to which they affect the rectal wall layers (Karantanas et al., 2007). The prefix " $u$ " is used to represent stage and it corresponds to the TNM classification (Smith \& Brown, 2008).

- $\quad$ uT1 - tumour does not penetrate the muscularis propria.

- $\quad$ uT2 - tumour penetrates the muscularis propria but not beyond it.

- $\quad$ uT3 - tumour proceeds beyond the muscularis propria, infiltrating the perirectal fat to a variable degree.

- $\quad$ uT4 - tumour infiltrates surrounding organ (Giovannini \& Ardizzone, 2009).

There have been meta-analyses carried out to determine the value of ERUS. It has been found to be very accurate for the staging of superficial rectal tumours, with accuracy in evaluating tumour ingrowths into rectal wall layers ranging from $69 \%$ to $97 \%$ (Gualdi et al., 
2000). Furthermore, the sensitivity and specificity of ERUS to diagnose stage T1 cancer were $87.8 \%$ and $98.3 \%$, respectively; for stage T2 the sensitivity and specificity were $80.5 \%$ and 95.6\% respectively; for stage $\mathrm{T} 3$ the sensitivity and specificity were $96.4 \%$ and $90.6 \%$ respectively; for stage T4 the sensitivity and specificity were $95.4 \%$ and $98.3 \%$ respectively (Puli et al., 2009). ERUS is also good for differentiating early and advanced rectal lesions with a sensitivity of $96 \%$, a specificity of $85 \%$ and an accuracy of $94 \%$ (Zorcolo et al., 2009). Also, there are data to suggest that ERUS is $62 \%$ to $92 \%$ accurate for T-staging and $64 \%$ to $88 \%$ accurate for N-staging (Geibel \& Longo, 2006).

High-resolution three-dimensional ERUS is useful for assessing the depth of submucosal invasion in early rectal cancer and for selecting therapeutic options. Santoro et al. (2009) evaluated the accuracy of this modality in distinguishing slight from massive submucosal invasion of early rectal tumours in a prospective study. The depth of invasion was correctly determined in $87.2 \%$ of both pT1-slight and pT1-massive lesions. It also had an accuracy of 95.2\% in selecting appropriate management. A meta-analysis by Puli et al. (2010) also showed that ERUS had a sensitivity of 97.3\% (95\% CI: 93.7-99.1) and specificity of 96.3\% (95\% CI: 95.3-97.2) in diagnosing T0. Such excellent sensitivity can help physicians offer endoscopic treatment to patients with $\mathrm{T} 0$ stage rectal cancers.

Through various research and clinical practice, ERUS has been found to be a safe and accurate method for staging rectal carcinoma, although it is operator-dependent. For this reason, adequate training and skill-development is essential.

Other imaging modalities used for preoperative staging of rectal carcinoma include computed tomography (CT) scan, magnetic resonance imaging (MRI) and positron emission tomography (PET) scan (Geibel \& Longo, 2006).

An abdominopelvic CT scan is performed on the majority of patients with clinically localised rectal cancer in order to identify any intra-abdominal metastasis prior to curative or radical resection. However, its role in preoperative staging is much more limited with accuracy of T-staging being $53 \%$ to $94 \%$ and for N-staging $54 \%$ to $70 \%$, which are substantially lower than ERUS (Schaffzin \& Wond, 2004).

MRI is also less accurate than ERUS for staging rectal cancer, with an accuracy of $52 \%$ in T-stage and $68 \%$ in N-stage (Chen et al., 2000). Most of the inaccuracy is due to overstaging caused by inability of MRI to differentiate treatment-induced fibrosis from viable tumours.

Genetic and molecular research has also been performed by Zlobec, et al (2008), which aimed to determine an immunohistochemical protein profile to complement preoperative staging and identify rectal carcinoma patients at a high risk of an adverse outcome. Eight protein markers were selected for use in the investigation, based on their correspondence to various cellular processes and their prognostic value. These protein markers were APAF-1, EphB2, MSTI, Ki67, p53, RHAMM, RKIP and CD8+ tumour infiltrating lymphocytes (TL). 482 patients were retrospectively collected from three different centres in Switzerland. The inclusion criteria comprised of those patients with primary colorectal cancer who received treatment between 1987 and 1996. Patients were excluded from the study if their tumours were located in the colon or if the rectal carcinoma had been treated preoperatively. Clinicopathological features recorded for each participant included gender, $\mathrm{pT}$ and $\mathrm{pN}$ stage, tumour grade, vascular invasion, invasive margin, mismatch repair, recurrence, metastasis, postoperative therapy and 5-year survival. Follow-up reached 150 months. 
Initial univariate survival analysis (Cox proportional hazards regression) for each protein marker showed that four markers were linked to survival time, including negative expression of Ki67, positivity for RHAMM, absence of RKIP and loss of CD8+ TILs. Further multivariable analysis found that only RHAMM $(\mathrm{p}<0.001 ; \mathrm{HR}=1.94(1.44-2.61))$ and loss of CD8+ TILs ( $\mathrm{p}=0.006$; HR= $0.63(0.45-0.88)$ ) were independent prognostic factors.

Therefore, this study proposes that the immunohistochemical protein profile of RHAMM and CD8 ${ }^{+}$TILs can identify patients with adverse prognosis independent of the extent of the disease and. Collectively, they could aid in selecting early stage rectal cancer patients who are predominantly more likely to have poorer prognosis and thus will benefit the most from preoperative treatment.

\section{Management}

Radical surgery with total mesorectal excision (anterior resection and abdominoperineal excision) remains the 'gold standard' treatment for rectal cancer. Through this operation, both the primary tumour and the draining lymph nodes are removed which, in turn, leads to a reduction in recurrence. Although it gives the best chance of cure but have a significant risk of death (30-day mortality rate $<7 \%)$, morbidity $(35 \%)$ and poor functional outcome (Association of Coloproctology of Great Britain and Ireland, 2007). One retrospective study evaluated 168 patients with T1-stage rectal cancer and found radical resection to have a local recurrence, distant recurrence and estimated 5-year overall recurrence of 3\%, 3\% and 6\%, respectively (Bentrem et al., 2005).

On the other hand, local treatment in the management of early rectal cancer aims to minimize morbidity and mortality but at the same time to offer cure. The importance of early diagnosis and local treatment options has been highlighted by the increasing numbers of early rectal cancer detected through the introduction of bowel screening programme, an increasing elderly population associated with multiple co-morbidities and the significant number of patients who are 'stoma phobic' and refuse conventional major surgery. The decision to offer local treatment for early rectal cancer must involve all members of the multidisciplinary team.

Staging of the early rectal cancer is critical. Clinical staging of rectal cancer is based on TNM classification (Table 1). Histological assessment plays the most important factor in predicting the risk of lymphatic spread.

When selecting patient for local treatment, the aim is to choose those with tumours confined to rectal wall with a low probability of lymph node metastases. Patients can be assessed by digital rectal examination supplemented by endoscopy and radiology [endorectal ultrasound or endorectal magnetic resonance imaging (MRI)]. Selection criteria and exclusion criteria for local treatment are summarized in table 3 and 4 (Hershman et al., 2003).

Various local treatment options available will be discussed in the following paragraphs. However, combinations of local treatment options i.e. combined modality approach have been used successfully in treating early rectal cancer.

\subsection{Local surgical options}

\subsubsection{Endoscopic Mucosal Resection (EMR)}

EMR is usually reserved for benign pedunculated or flat polyps. In the treatment of rectal cancer, it is suitable for very early malignant T1 tumours (sm1 or selected sm2) (Table 2) 
(Kikuchi et al., 1995). It is performed under sedation without the requirement of general anaesthesia. Hence, it is a major advantage for very unfit patients.

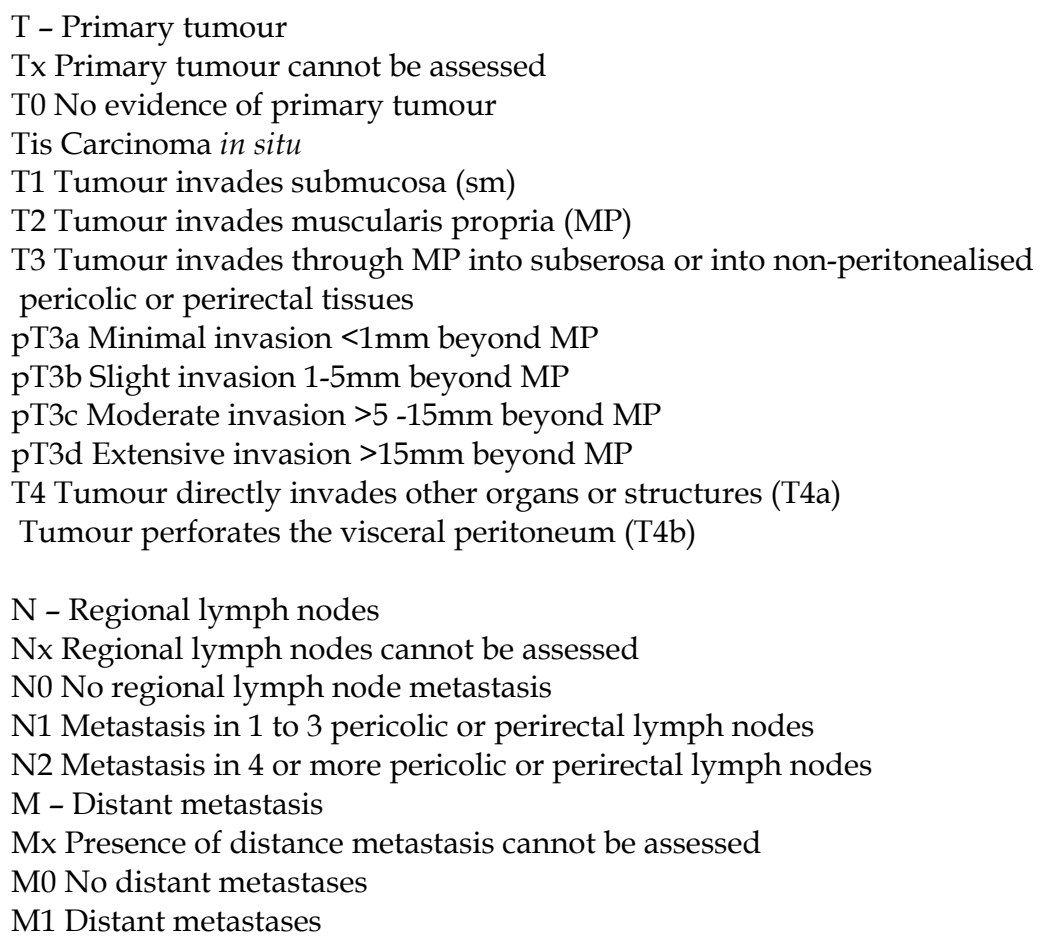

Table 1. TNM Staging.

\begin{tabular}{|l|l|l|}
\hline \multicolumn{3}{|c|}{ Classification of submucosal invasion by early colorectal cancer } \\
\hline \multirow{3}{*}{ Sm1 } & a & $<1 / 4$ of the width of the tumour invading the submucosa \\
\cline { 2 - 3 } & b & $1 / 4$ or $1 / 2$ the width of the tumour invading the submucosa \\
\cline { 2 - 3 } & c & $>1 / 2$ the width of the tumour invading the submucosa \\
\hline Sm2 & Intermediate between Sm1 and Sm3 \\
\hline Sm3 & Carcinoma invasion near to the muscularis propria \\
\hline
\end{tabular}

Table 2. Classification of submucosal invasion by early colorectal cancer according to Kikuchi et al. (1995). 


\section{Selection criteria for suitability of local treatment}

1. Mobile non-ulcerative exophytic tumours $<10 \mathrm{~cm}$ from anal verge (clinical assessment: digital rectal examination)

2. Tumour $<3 \mathrm{~cm}$ or occupying less than $1 / 3$ of the circumference (endoscopic assessment)

3. $\mathrm{cT} 1 / \mathrm{Tx} / \mathrm{cN} 0 / \mathrm{cM} 0$ (radiological assessment: endorectal ultrasound/ MRI

4. Well to moderately well differentiated tumours (histological assessment)

5. No lymphovascular or venous invasion (histological assessment)

6. Patient must agree on long-term follow up

Table 3. Selection criteria for local treatment based on clinical practice of Dr. S Myint and Mr. M J Hershman.

\section{Exclusion criteria for local treatment}

1. Poorly differentiated tumour.

2. T3/T4 tumour

3. Clinically tethered or fixed tumour of any radiological $\mathrm{T}$ stage

4. Deeply infiltrative ulcerative tumour

Table 4. Exclusion criteria for local treatment based on clinical practice of Dr. S Myint and Mr. M J Hershman.

During EMR, the polyp is assessed endoscopically, its base is then infiltrated by normal saline or gel to raise it away from the underlying muscle before it is resected using a diathermy or a hot loop. The specimen is then pinned and oriented for histological submission. EMR may not be appropriate if the polyp's base cannot be raised suggesting the tumour is probably more advanced.

The selection criteria for EMR in early rectal cancer are controversial, but generally include (Onozato et al., 2007):

- Well or moderately differentiated adenocarcinoma

- The mucosal or minute submucosal type

- No lymphatic or vascular invasion

No large studies have compared the effectiveness of EMR with transanal excision. A small retrospective study suggested that EMR was a safe and effective method for the treatment of early rectal cancer and its outcomes were comparable to those of transanal excision procedures (Lee et al., 2009) (complete resection was 93.8\% for EMR vs. 87.5\% for transanal excision; mean length of hospital-stay was 2.7 for EMR vs. 8.9 for transanal excision; no recurrence disease in either group at median follow up of 15 months). There were no significant differences between the two study groups with regard to rectal cancer size, location from the anal verge and histological differentiation.

A prospective study in Sheffield, UK suggested extended EMR for rectal neoplastic lesions can achieve superior results to those of per-anal excision and trans-anal microsurgery with regard to complications and recurrence rates (Hurlstone et al., 2005). The 30-day 
readmission and death rate was $0 \%$, bleeding $8 \%$; no procedural related complications or perforation with overall 'cure' rate of $98 \%$ at a median follow-up of 16 months.

\subsubsection{Transanal Resection (TAR) / Transanal Endoscopic Microsurgery (TEM)}

Locoregional treatment for early rectal cancer is gaining popularity compared with standard treatment of radical surgery (anterior or abdominoperineal resection). Local procedures for strictly selected patients should lead to similar oncological results and even better outcomes in terms of morbidity, mortality and quality of life (Moore \& Guillem, 2002).

Conventional TAR allows the excision of tumours in the lower rectum using anal retractors. Preoperative staging is very important in determining TAR as an option for treating early rectal cancer. It is generally agreed that the criteria for TAR are (Stamos \& Murrell, 2007):

- Mobile, non ulcerated T1 or T2 tumour

- Nodes negative on ultrasound

- $\quad<8 \mathrm{~cm}$ from anal verge

- Occupying $<1 / 3$ of the circumference

- Low grade tumours (well or moderately differentiated)

- Favourable histology on biopsy without lymphovascular invasion

It should be performed as a full thickness resection down to perirectal fat, along with a $1 \mathrm{~cm}$ radial margin. The defect is usually closed but it can be left open. The specimen should then be pinned and oriented for histology submission.

TAR is associated with relatively low morbidity and mortality, decreased hospital stay and has minimal effect on sphincter function. However, this technique is associated with relatively high rates of local recurrence when compared with standard excision $(11.0 \% \mathrm{vs}$. $1.6 \% ; 13.2 \%$ vs. $2.7 \%$ ) especially in patients with a high-grade tumour, or perineural or lymphovascular invasion (Nash et al., 2009; Peng et al., 2011).

If there are unfavourable pathological features like positive resection margins, lymphovascular invasion, lymph node metastasis, perineural invasions and recurrent lesion at follow-up; salvage surgery must be considered.

In summary, TAR has low morbidity and mortality, rapid recovery times and allows preservation of sphincter function but is associated with higher rate of recurrence especially high grade tumour and those with perineural or lymphovascular invasion. Therefore, it is essential to have strict selection criteria when considering this technique and patients should be informed of the risk of local recurrence and the need of frequent follow up.

TEM was first described by Buess in 1984 (Buess et al., 1983, 1984). A resectoscope is used to give stereoscopic view of the rectum and distal sigmoid colon. The rectum is distended with insufflated carbon dioxide to allow the passage of dissecting instruments. It has an exceptionally clear magnified view of the mucosa allows precise removal of mucosal lesions and avoiding the need for radical surgery. TEM is theoretically suitable for tumours lying up to $25 \mathrm{~cm}$ from the anal verge, unlike TAR which only offers overview of the lower rectum. However, the procedure is usually used for tumours below the peritoneal reflection due to risk of intraperitoneal perforation, technical difficulty and unavailability of preoperative staging with endorectal ultrasonography for proximally sited tumours (Sharma et al., 2003).

TEM represents an effective curative treatment for pT1 sm1 rectal malignancies. A prospective study included 107 patients who had adenocarcinoma: 48 pT1, 43 pT2, and 16 pT3; the 5-year disease-free survival rate was $85.9 \%, 78.4 \%$, and $49.4 \%$ respectively 
$(\mathrm{p}=0.006)$. Recurrence rate was $0 \%(0 / 26)$ in pT1sm1 cancers and $22.7 \%(5 / 22)$ in sm2-3 $(\mathrm{p}<0.05)$ (Morino et al., 2011). A submucosal infiltration represented a significant risk factor for recurrences: $0 \% \mathrm{sm} 1,16.7 \% \mathrm{sm} 2$, and $30 \% \mathrm{sm} 3$.

Another prospective study (Ramirez et al., 2011) also supports transanal endoscopic microsurgery as an adequate treatment for T1 low-risk tumour and no additional measures are required. The five-year overall survival was $94 \%$ and cancer-specific survival was $96 \%$. In addition, the quality of resection is better with TEMS than with TAR as shown in a retrospective study with 42 TEM and 129 TAR patients (Christoforidis et al., 2009).

The reasons for the superiority of TEM over TAR include:

- The use of an optical system with 3D-view

- 6-fold magnification

- The creation of a stable pneumorectum

- Specially designed instruments allow full-thickness excision under direct observation in the lower, middle and even upper parts of rectum

- Full thickness excision allows proper histological examinations

There are no large head to head studies comparing TEM with conventional radical surgery. There is 1 small prospective randomized trial and 2 retrospective cohort studies comparing TEM with radical surgery (Heintz et al., 1998; Lee et 1., 2003; Winde et al., 1996) (Table 5). According to study by Winde et al, there was no significant difference in the local recurrence rate or the survival rate for patients treated with TEM or anterior resection. However, the power of the study was inadequate. Lee et al also reported similar outcomes for patients with T1 and T2 rectal cancers underwent TEM or radical surgery. Study by Heintz et al is difficult to interpret due to inclusion of patients who had inadequate local surgery.

TEM is a safe technique with low morbidity and recurrence rates (Koebrugge et al., 2009). Experience over times has led to a reduction in operation time, length of patients' hospital stay and complication rate. TEM remains the treatment of choice for stage T1 low risk rectal carcinomas. Patient with pT1 sm2-3 and T2 low risk lesions should be considered high-risk cases if treated only by TEM (Morino et al., 2011; Ramirez et al., 2011).

\subsection{Contact radiotherapy}

Rectal adenocarcinoma is radio-resistant. Doses above 80Gy are necessary and need to be delivered by endocavitary irradiation (contact $x$-ray therapy, brachytherapy) with high doses targeting the tumour but low doses to normal tissue.

Contact radiotherapy or known as Papillon's technique was developed in the 1950s and is performed with a $50 \mathrm{kV}$ hand held tube which is capable of delivering a dose of 20 Gy per minute. The percentage dose is $100 \%$ at $0 \mathrm{~mm}$, about $50 \%$ at $5 \mathrm{~mm}$ depth and $20 \%$ at $10 \mathrm{~mm}$. The scatter from the tube is negligible.

For a T1N0 tumour, treatment is divided into 4 sessions:

- $\quad 35$ Gy on day 1

- $\quad 30$ Gy on day 7

- 20 - 25 Gy on day 21

- 10 - 20 Gy on day 35

The total dose may range from $80-110$ Gy in four to five fractions depending on the initial size of the tumour and the shrinkage of the tumour which is measured on day 21 . If a 
complete response is achieved at this stage, the chance of control with radiotherapy alone is very high. However, if there is still a visible lesion, patient should be referred for surgery or the dose increased to $100-120$ Gy and combined with external-beam radiotherapy and a brachytherapy boost if inoperable.

\begin{tabular}{|c|c|c|c|c|c|c|}
\hline Study & T Stage & $\begin{array}{l}\text { TEM / } \\
\text { Radical } \\
\text { surgery (RS) }\end{array}$ & $\begin{array}{l}\text { Number of } \\
\text { patients }\end{array}$ & \begin{tabular}{|l} 
Local \\
recurrence rate \\
$(\%)$
\end{tabular} & $\begin{array}{l}\text { Overall } \\
\text { survival } \\
\text { rate }(\%) \\
\end{array}$ & $\begin{array}{l}\text { Follow-up } \\
\text { (Months) }\end{array}$ \\
\hline \multirow{2}{*}{$\begin{array}{l}\text { Winde et al } \\
(1996)\end{array}$} & \multirow{2}{*}{1} & TEM & 24 & 4.2 & 96 & \multirow{2}{*}{46} \\
\hline & & RS & 26 & 0 & 96 & \\
\hline \multirow{4}{*}{ Lee et al (2003) } & \multirow{2}{*}{1} & TEM & 52 & 4.1 & 100 & \multirow{4}{*}{$31-35$} \\
\hline & & RS & 17 & 0 & 93 & \\
\hline & \multirow{2}{*}{2} & TEM & 17 & $19.5(\mathrm{p}<0.05)$ & 95 & \\
\hline & & RS & 83 & 9.4 & 96 & \\
\hline \multirow{4}{*}{$\begin{array}{l}\text { Heintz et al } \\
(1998)\end{array}$} & \multirow{2}{*}{$\begin{array}{l}1 \\
\text { (Low } \\
\text { risk) }\end{array}$} & TEM & 46 & 4.4 & 79 & \multirow{4}{*}{$42-52$} \\
\hline & & RS & 34 & 2.9 & 81 & \\
\hline & \multirow{2}{*}{$\begin{array}{l}1 \\
\text { (High } \\
\text { risk) }\end{array}$} & TEM & 12 & 33 & 62 & \\
\hline & & RS & 11 & 18.2 & 69 & \\
\hline
\end{tabular}

Table 5. Summary of results for TEM vs. Radical surgery studies.

Gerald et al (2002) reported contact radiotherapy can achieve local control in $85-90 \%$ of patients with T1N0 tumours, good tolerability in most with preservation of good anorectal function and no severe late toxic effects.

Sun Myint et al (2007) at Clatterbridge, UK reported their experience of treating patients with early rectal cancer using multimodality approach including contact radiotherapy. Clatterbridge uses the Therapax $50 \mathrm{kV}$ machine with a $0.5 \mathrm{~mm}$ Al filter as opposed to the Philips machine. At Clatterbridge, patients who do not respond well to initial contact radiotherapy are offered external-beam radiotherapy alone, delivering 45Gy in 20 fractions over 4 weeks or chemoradiotherapy with 45Gy in 25 fractions over 5 weeks with 5 -fluorouracil infusion $750-1000 \mathrm{mg} / \mathrm{m} 2$ in weeks 1 and 5.5 -fluorouracil has been changed to oral capecitabine $825 \mathrm{mg} / \mathrm{m} 2$ on the days of radiotherapy. From their experience, 124 out of 220 patients had Papillon's contact radiotherapy as part of the multimodality treatment. There were 24/220 (11\%) with residual disease after initial radiotherapy. $71 \%$ of patients were still alive at a median follow-up of 4.6 years. The cancer specific survival was $93 \%$.

Therefore, contact therapy is an efficient treatment for T1N0 rectal adenocarcinoma. It has the advantage of not needing general anaesthesia, can be performed on an outpatient basis, can be used to treat frail elderly patients and no risk of fistula.

For T2-3N0-1 tumours, the standard treatment is radical surgery. However, this may not be suitable if the patient has high co-morbidity or patient refuses to have permanent colostomy. 
In these situations, a combination of contact radiotherapy and external-beam radiotherapy, brachytherapy or both may be considered. The combination treatment is essential as contact therapy alone is insufficient to penetrate the deeper layers of the rectal wall and no irradiation reaches the perirectal lymph nodes which are at high risk of involvement.

\subsection{Local excision and adjuvant therapy}

Postoperative radiation and chemotherapy have been used as an alternative to radical surgery to reduce the risk of local recurrence for patients. There are studies to suggest lower trends of local recurrence rates and higher disease free survival (DFS) rates with adjuvant therapy compared with local excision alone, especially in T2 tumours or in higher grade tumours.

Retrospective study by Chakravarti et al (1999) compared patients with T1/T2 rectal cancer treated by local excision alone with those treated by local excision plus adjuvant radiation therapy. There was no difference in the 5-year local recurrence and DFS between the 2 groups even though there were significantly higher proportions of T2 tumours and T1 tumours with unfavourable histological features in the radiation therapy group. However, subgroup analysis of high-risk patients showed substantially better local control rate with the addition of postoperative radiation ( $85 \%$ vs. $37 \%$ local excision alone).

A prospective multi-institutional trial by The Cancer and Leukaemia Group B comparing the outcomes of 59 patients with T1 lesions treated with local excision alone with those 51 patients with T2 lesions treated with local excision and postoperative chemoradiation (Greenberg et al., 2008). The recurrence rates were 7\% for the T1 and $14 \%$ for $\mathrm{T} 2$ at a median follow-up of 7 years.

The Radiation Oncology Therapy Group study evaluating adjuvant chemoradiation therapy after local excision reported a 16\% (8 out of 65) locoregional recurrence rate (Russell et al., 2000). The risk of recurrence correlated with T stage (T1 4\%, T2 16\%, T3 23\%).

Despite the lack of randomized control trials, there are data to support benefit of adjuvant chemoradiation or radiation therapy after local excision for patients with T2 or in highergrades tumours. More studies are still required before this can be adopted to routine clinical practice.

\subsection{Local excision after neoadjuvant therapy}

Local excision after neoadjuvant therapy may be considered for patients who refuse radical surgery or candidates who are at high risk of surgery due to significant medical comorbidities.

Lezoche et al (2005) reported 2.8\% (1 out of 106) recurrence rate in T2 rectal cancer patients treated with preoperative chemoradiotherapy followed by TEM at a median follow up of 38 months. This group has further conducted a randomised trial of preoperative chemoradiotherapy followed by TEM vs. radical surgery alone. This trial showed equivalent local control and survival at a median follow-up of 4-years however this study did not have adequate study power.

Although robust evidence is still lacking to support the routine use of neoadjuvant therapy with local excision, the tumoricidal effect of neoadjuvant chemoradiation is well documented in patients with advanced rectal cancer treated with radical surgery. Hence, it is reasonable to project the benefits of neoadjuvant therapy in treating patients with early rectal cancer by local excision especially in T2 tumours. 


\subsection{Salvage surgery after local excision}

Salvage surgery can be offered to patients who have failed local treatment of early rectal cancer. There are two types available:

- Immediate salvage (rescue surgery)

- This is performed within 6 months of the completion of local treatment.

- This includes patients with inadequate resection margins of local surgery, unfavourable pathology and failure to eradicate tumour with local treatment.

- Delayed salvage

- This is carried out for local recurrence after an apparent cure of cancer that has been sustained for a minimum of 3 months.

Hershman and Sun Myint (2007) reported that salvage surgery was an effective management after fail local treatment with an overall salvage rate of $68 \%(30 / 44)$ and a salvage cure rate of $87 \%(26 / 30)$. Mellgren et al (2000) reported a 5-year disease-free survival rate of $50 \%$ in 24 out of 25 patients with local recurrence treated with radical salvage surgery.

Therefore, intensive follow-up after initial local treatment in the first 3 years is important in order to identify patients who are suitable for salvage surgery and to enable prompt treatment.

Treatment Algorithm for Patients with Early Rectal Cancer are summarised in Table 6.

\section{Complications}

\subsection{EMR}

EMR is usually tolerated without many side effects. However, bleeding and recurrence has been reported especially for those with submucosal cancer. A retrospective study by Kim et al (2011) reported that 7 out of the 65 patients with submucosal cancer who underwent EMR showed adverse outcomes within 3 years: recurrence or residual of primary cancer or lymph node metastasis.

Metz et al (2011) reported 7\% (21 out of 288 patients) experienced clinically significant delayed bleeding after undergoing EMR for laterally spreading tumours of $20 \mathrm{~mm}$ or greater. 10 underwent colonoscopy, 1 required angiography and 1 required surgery after perforation following hemostatic clip placement. These were data analysed from two large prospective intention-to-treat studies of EMR. Their data have shown that proximal lesion location is a highly significant risk for clinically significant delayed bleeding following colonic EMR. Recent aspirin use also increases bleeding risk. Surprisingly, larger lesion size $(\mathrm{P}=0.2)$, multiple excisions rather than en bloc resection $(P=0.1)$, polyp morphology $(P=0.2)$, and previous attempts $(\mathrm{P}=0.5)$ are not associated with increased risk of bleeding.

\subsection{TAR}

TAR has been reported to be associated with local recurrence in the treatment for early rectal cancer. Taylor et al (1998) report a 30\% recurrence rate for T1 and T2 tumours treated by local excision alone, Grarcia-Anguilar et al (2000) reported 18\% recurrence with T1 tumours and $37 \%$ with T2 tumours at 54 months of follow up, Madbouley et al (2005) reported overall recurrence rate of a $28.8 \%$ in T1 rectal cancer and Huh et al (2009) reported similar recurrence rate of $28.5 \%$ in early rectal tumours with favourable pathologic features at median follow-up of 66 months. 
Local excision does not remove lymph nodes in the mesorectum, therefore, when considering patients for local excision, strict selection criteria are essential to give more favourable outcomes. Risk of lymph nodes involvement is $0-12 \%$ for T1 cancer and $12-28 \%$ for T2 cancers (Sengupta \& Tjandra, 2001). Features associated with a significantly increased risk of lymph node metastases include poor differentiation, lymphovascular invasion and size greater than $3 \mathrm{~cm}$ (Chambers et al., 2004; Nascimbeni et al., 2002).

\subsection{TEM}

Although TEM represents an effective curative treatment for pT1 sm1 rectal cancer, it can be associated with recurrence in pT1 sm2-3 patients. Study by Morino et al (2011) showed that recurrence rate was $0 \%(0 / 26)$ in pT1sm1 cancers and $22.7 \%(5 / 22)$ in $\mathrm{sm} 2-3(\mathrm{p}<0.05)$. In addition, other risk factors associated with recurrence include pT2 leisons and lesions larger than $3 \mathrm{~cm}$. Acording to a retrospective study by $\mathrm{Yu}$ et al (2011) involving 60 patients who underwent TEM, there was a significant difference in local recurrence rate between pT1 and pT2 $(2.6 \%$ vs. $40.0 \%, \mathrm{P}<0.05)$. The recurrence rate was higher in lesions larger than $3 \mathrm{~cm}$ compared to those lesions smaller than $3 \mathrm{~cm}(19.0 \%, 4 / 21$ vs. $2.6 \%, 1 / 39$, $\mathrm{P}<0.05)$ (Yu et al., 2011).

\subsection{Contact radiotherapy}

The main side effect of endocavitary irradiation (contact radiotherapy with or without iridium brachytherapy) combined with external-beam radiotherapy is rectal bleeding, which may require argon laser treatment. Other side effects include bowel urgency and frequency in the morning which do not generally affect normal life (Gerald et al., 2002). Late toxic effects include rectal fibrosis or stenosis and rectal ulcers with persistent bleeding leading to chronic anaemia have been reported (Birnbaum et al., 1994; Cho et al., 1995; Letschert, 1995).

\section{Conclusion}

Local treatment of early rectal cancer remains an attractive alternative to radical surgery in the current climate of increasing ageing population and the numbers of early rectal cancer detected through colorectal screening programme. This option is suitable for elderly patients, those patients with significant medical co-morbidities who are at increased operative risk and those who are stoma averse. Unlike radical surgery, it is associated with relatively low morbidity and mortality, decreased hospital stay and has minimal effect on sphincter functions. Although this treatment option is still debated, local excision alone should be used for selected patients with T1 tumours or low risk T2 tumours and patients should be informed of the risk of local recurrence and the need of frequent follow up. Contact radiotherapy is an efficient treatment for T1N0 rectal adenocarcinoma. It has the advantage of not needing general anaesthesia, can be performed on an outpatient basis, can be used to treat frail elderly patients and no risk of fistula. A combination of contact radiotherapy and external-beam radiotherapy, brachytherapy or both may be considered for patients with T2-3N0-1 tumours. Salvage surgery can be offered to patients with recurrences. Combination of local excision with adjuvant and neoadjuvant therapies may play a role in the treatment of early rectal cancer but more trials are needed. Patients and relatives should be informed fully regarding treatment options available and the side effects associated with each treatment. Careful selection of patient and preoperative staging are paramount for the successful outcome of multimodality approach and all multidisciplinary team members must be involved in order to deliver high quality of care to patients. 


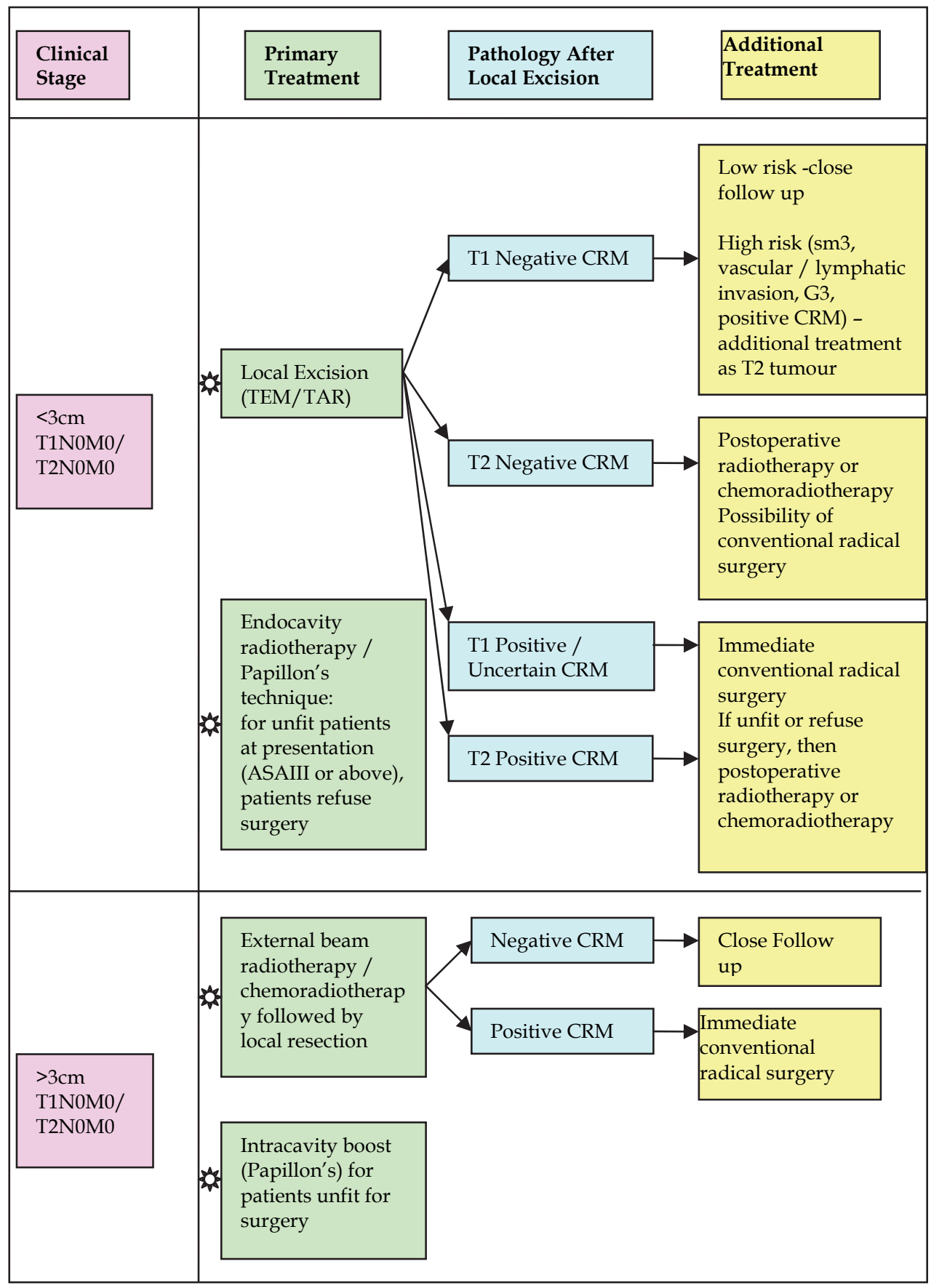

Table 6. Treatment Algorithm for Patients with Early Rectal Cancer. 


\section{Acknowledgment}

Very grateful to Dr. Caroline Angit for her help in preparing and formatting the manuscripts.

\section{References}

Association of Coloproctology of Great Britain and Ireland. Guidelines for the Management of Colorectal Cancer (3rd edn). 2007.

http://www.library.nhs.uk/theatres/Viewresource.aspx?res ID=31479.

Bentrem, D.J.; Okabe, S.; Wond, D. \& et al. (2005). T1 adenocarcinoma of the rectum. Transanal excision or radical surgery? Ann Surg, Vol. 242, pp. 472-477.

Bhutani, M.S. (2009). Colorectal endoscopic ultrasound, In: Gress FG, Savides TJ, editors. Endoscopic ultrasonography (2nd ed), 160-171. West Sussex: Wiley-Blackwell.

Birnbaum, E.H.; Myerson, R.J. \& Fry, R.D. et al. (1994). Chronic effects of pelvic radiation therapy on anorectal function. Dis Colon Rectum,Vol.37, pp.909-915.

Buess, G.; Theiss, R.; Hutterer, F.; Pichlmaier, H.; Pelz, C.; Holfeld, T. et al. (1983). Transanal endoscopic surgery of the rectum - testing a new method in animal experiments. Leber Magen Darm, vol.13, pp.73-77.

Buess, G.; Hutterer, F.; Theiss, J.; Bobel, M.; Isselhard, W. \& Pichlmaier, H. (1984). A system for a transanal endoscopic rectum operation. Chirurg, Vol.55, pp. 677-680.

Chakravarti, A.; Compton, C.C.; Shellito, P.C.; Wood, W.C.; Landry, J.; Machuta, S.R.; Kaufman, D.; Ancukiewicz, M. \& Willett, C.G. (1999). Long-term follow-up of patients with rectal cancer managed by local excision with and without adjuvant irradiation. Ann Surg, Vol.230, No.1, pp. 49-54.

Chambers, W.M.; Khan, U.; Gagliano, A.; Smith, R.D.; Sheffield, J. \& Nicholls, R.J. (2004). Tumour morphology as a predictor of outcome after local excision of rectal cancer. Br J Surg, Vol.91, No.4, pp.457-459.

Chen, C.C.; Lee, R.C. ; Lin, J.K. \& et al. (2000). How accurate is magnetic resonance imaging in restaging rectal cancer in patients receiving preoperative combined chemoradiotherapy? Dis Colon Rectum, Vol.82, pp. 967-981.

Cho, K.H.; Lee, C.K.K. \& Levit, S.H. (1995). Proctitis after conventional external radiation therapy for prostate cancer: importance of minimizing posterior rectal dose. Radiology, Vol.3, pp.699-703.

Christoforidis, D.; Cho, H.M.; Dixon, M.R.; Mellgren, A.F.; Madoff, R.D. \& Finne, C.O. (2009). Transanal endoscopic microsurgery versus conventional transanal excision for patients with early rectal cancer. Ann Surg, Vol.249, No.5, pp.776-782.

Day, D.W.; Jass, J.R,; Price, A.B.; Shepherd, N.A.; Sloan, J.M.; Talbot, I.C. \& et al. (2003). Epithelial tumours of the large intestine, In: Morson and Dawson's Gastrointestinal Pathology (4th edn), 551-609. Blackwell Science: Oxford.

Garcia-Aguilar, J.; Mellgren, A.; Sirivongs, P.; Buie, D.; Madoff, R.D. \& Rothenberger, D.A. (2000). Local excision of rectal cancer without adjuvant therapy: a word of caution. Ann Surg, Vol.231, pp.345-351.

Geibel, J. \& Longo, W. (2006). Modern management of rectal cancer: A 2006 update. World J Gastroenterol, Vol.12, No.20, pp.3186-3195. 
Gerald, J.P.; Chapet, O. \& Ramaioli, A. (2002). Long term control of T2 - T3 rectal adenocarcinoma with radiotherapy alone. Int J radiol Oncol Biol Phys, Vol.54, pp.142-149.

Giovannini, M. \& Ardizzone, S. (2009). Anorectal ultrasound for neoplastic and inflammatory lesions. Best Prac Res Clin Gastroenterol, Vol.44, pp.100-107.

Greenberg, J.A.; Shibata, D.; Herndon, J.E.; Steele, G.D.Jr.; Mayer, R. \& Bleday, R. (2008). Local excision of distal rectal cancer: an update of cancer and leukemia group B 8984. Dis Colon Rectum, Vol.51, No.8, pp.1185-1191.

Gualdi, G.F.; Casciani, E.; Guadalaxara, A. \& et al. (2000). Local staging of rectal cancer with transrectal ultrasound and endorectal magnetic resonance imaging: comparison with histologic findings. Dis Colon Rectum, Vol.43, pp. 338-345.

Heintz, A.; Mörschel, M. \& Junginger, T. (1998). Comparison of results after transanal endoscopic microsurgery and radical resection for T1 carcinoma of the rectum. Surg Endosc, Vol.12, pp. 1145-1148.

Hershman, M.J.; Sun Myint, A. \& Makin, C.A. (2003). Multi-modality approach in curative local treatment of early rectal carcinomas. Colorectal Dis, Vol.5, pp. 445-450.

Hershman, M.J. \& Sun Myint, A. (2007). Salvage surgery after inadequate combined local treatment for early rectal cancer. Clinc Onc, Vol.19, pp.720-723.

Huh, J.W.; Park, Y.A.; Lee, K.Y.; Kim, S.A. \& Sohn, S.K. (2009). Recurrences after local excision for early rectal adenocarcinoma. Yonsei Med J, Vol.31, No.50, pp.704-708.

Hurlstone, D.P.; Sanders, D.S.; Cross, S.S; George, R.; Shorthouse, A.J. \& Brown, S. (2005). A prospective analysis of extended endoscopic mucosal resection for large rectal villous adenomas: an alternative technique to transanal endoscopic microsurgery. Colorectal Dis, Vol.7, No.4, pp. 339-344.

Jeffreys, M.; Rachet, B.; McDowell, S. \& et al. (2006). Survival from rectal and anal cancers in England and Wales, 1986-2001. Eur J Cancer, Vol.42, pp.1434-1440.

Karantanas, A.H.; Yarmenitis, S.; \& Papanikolaou, N. \& et al. (2007). Preoperative imaging staging of rectal cancer. Dig Dis, Vol.25, pp.20-32.

Kikuchi, R.; Takano, M.; Takagi, K.; Fujimoto, N.; Nozaki, R.; Fujiyoshi, T. \& Uchida, Y. (1995). Management of early invasive colorectal cancer. Risk of recurrence and clinical guidelines. Dis Colon Rectum, Vol.38, No.12, pp.1286-1295.

Kim, M.N.; Kang, J.M.; Yang, J.I.; Kim, B.K.; Im, J.P.; Kim, S.G.; Jung, H.C. \& Song, I.S.; Kim, J.S. (2011). Clinical Features and Prognosis of Early Colorectal Cancer Treated by Endoscopic Mucosal Resection. J Gastroenterol Hepatol, Vol.22, (April 2011), pp. 1440-1746. [Epub ahead of print]

Koebrugge, B.; Bosscha, K. \& Ernst, M.F. (2009). Transanal endoscopic microsurgery for local excision of rectal lesions: is there a learning curve? Dig Surg, Vol.26, No.5, pp.372-7.

Lee, S.H.; Jeon, S.W.; Jung, M.K.; Kim, S.K. \& Choi, G.S. (2009). A comparison of transanal excision and endoscopic resection for early rectal cancer. World J Gastrointest Endosc, Vol.15, No.1, (Oct 2009), pp. 56-60.

Lee, W.; Lee, D.; Choi, S. \& et al. (2003.) Transanal endoscopic microsurgery and radical surgery for T1 and T2 rectal cancer. Surg Endosc, Vol.17, pp.:1283-1287. 
Letschert, J.G. (1995). The prevention of radio-induced small bowel complications. Eur J Cancer, Vol.31, pp. 1361- 1365.

Lezoche, E.; Guerrieri, M.; Paganini, A.M.; Baldarelli, M.; De Sanctis, A. \& Lezoche, G. (2005). Long-term results in patients with T2-3 N0 distal rectal cancer undergoing radiotherapy before transanal endoscopic microsurgery. Br J Surg, Vol.92, No.12, (Dec 2005), pp.1546-1552.

Madbouly, K.M.; Remzi, F.H.; Erkek, B.A.; Senagore, A.J.; Baeslach, C.M.; Khandwala, F. \& et al. (2005). Recurrence after transanal excision of T1 rectal cancer: should we be concerned? Dis Colon Rectum, Vol.48, pp.711-719.

Mellgren, A.; Sirivongs, P.; Rothenberger, D.A.; Madoff, R.D. \& García-Aguilar, J. (2000). Is local excision adequate therapy for early rectal cancer? Dis Colon Rectum, Vol.43, No.8, (Aug 2000), pp.1064-1071.

Metz, A.J.; Bourke, M.J.; Moss, A.; Williams, S.J.; Swan, M.P. \& Byth, K. (2011). Factors that predict bleeding following endoscopic mucosal resection of large colonic lesions. Endoscopy, Vol.43, No.6, (Jun 2011), pp.506-511.

Morino, M.; Allaix, M.E.; Caldart, M.; Scozzari, G. \& Arezzo, A. (2011). Risk factors for recurrence after transanal endoscopic microsurgery for rectal malignant neoplasm. Surg Endosc, (June 2011). [Epub ahead of print].

Moore, H.G. \& Guillem, J.G. (2002). Local therapy for rectal cancer. Surg Clin North Am, Vol.82, pp. 967-981.

Nascimbeni, R.; Burgart, L.J.; Nivatvongs, S. \& Larson, D.R. (2002). Risk of lymph node metastasis in T1 carcinoma of the colon and rectum. Dis Colon Rectum, Vol.45, No.2, pp. 200-206.

Nash, G.M.; Weiser, M.R.; Guillem, J.G.; Temple, L.K.; Shia, J.; Gonen, M.; Wong, W.D.\& Paty, P.B. (2009). Long-term survival after transanal excision of $\mathrm{T} 1$ rectal cancer. Dis Colon Rectum, Vol.52, No.4, pp. 577-582.

Onozato, Y.; Kakizaki, S.; Ishihara, H.; Iizuka, H.; Sohara, N.; Okamura, S.; Mori, M. \& Itoh, H. (2007). Endoscopic submucosal dissection for rectal tumours. Endoscopy, Vol.39, No.5, pp. 423-427.

Peng, J.; Chen, W.; Sheng, W.; Xu, Y.; Cai, G.; Huang, D. \& Cai, S. (2011). Oncological outcome of T1 rectal cancer undergoing standard resection and local excision. Colorectal Dis, Vol.13, No.2, pp. :e14-19.

Puli, S.R.; Bechtold, M.L.; Reddy, J.B.; Choudhary, A. \& Antillon, M.R. (2010). Can endoscopic ultrasound predict early rectal cancers that can be resected endoscopically? A meta-analysis and systematic review. Dig Dis Sci, Vol.55, No.5, pp.1221-1229.

Puli, S.R.; Bechtold, M.L.; Reddy, J.B. \& et al. (2009). How good is endoscopic ultrasound in differentiating various $\mathrm{T}$ stages of rectal cancer? Meta-analysis and systematic review. Ann Surg Oncol Vol.16, pp. 254-265.

Smith, N. \& Brown, G. Preoperative staging of rectal cancer. Acta Oncol Vol. 47, pp.20-31.

Ramirez, J.M.; Aguilella, V.; Valencia, J.; Ortego, J.; Gracia, J.A.; Escudero, P.; Esco, R. \& Martinez, M. (2011). Transanal endoscopic microsurgery for rectal cancer. Longterm oncologic results. Int J Colorectal Dis, Vol.26, No.4, pp. 437-443. 
Rex, D.K. (2000) American College of Gastroenterology Action Plan for Colorectal Cancer Prevention 2000: screening recommendations. Am J Gastroenterol Vol.95, pp.868-877.

Rex, D.K. (2004). Americal College of Gastroenterology Action Plan for Colorectal Cancer Prevention. Am J Gastroenterol, Vol.99, pp. 574-577.

Russell, A.H.; Harris, J.; Rosenberg, P.J.; Sause, W.T.; Fisher, B.J.; Hoffman, J.P.; Kraybill, W.G. \& Byhardt, R.W. (2000). Anal sphincter conservation for patients with adenocarcinoma of the distal rectum: long-term results of radiation therapy oncology group protocol 89-02. Int J Radiat Oncol Biol Phys, Vol.15, No.46, pp.313322.

Sant, M.; Aareleid, T.; Berrino, F. \& et al. (2003). EUROCARE-3: survival of cancer patients diagnosed 1990-94 - results and commentary. Ann Oncol, Vol.14, No.5, pp. v61v118.

Santoro, G.A.; Gizzi, G.; Pellegrini, L.; Battistella, G. \& Di Falco, G. (2009). The value of highresolution three-dimensional endorectal ultrasonography in the management of submucosal invasive rectal tumours. Dis Colon Rectum, Vol.52, No.11, pp.18371843.

Schaffzin, D.M. \& Wond, W.D. (2004). Endorectal ultrasound in the preoperative evaluation of rectal cancer. Clin colorectal Cancer, Vol.4, pp.124-132.

Sengupta, S.\& Tjandra, J.J. (2001). Local excision for rectal cancer: what is the evidence? Dis Colon Rectum, Vol.44, pp. 1345-1536.

Sharma, A.; Hartley, J. \& Monson, J.R. (2003). Local excision of rectal tumours. Surg Oncol, Vol.12, pp.51-61.

Siddiqui, A.A.; Fayiga, Y. \& Huerta, S. (2006). The role of endoscopic ultrasound in the evaluation of rectal cancer. Int Semin Surg Oncol, Vol.3 pp. 36.

Sobin, L.; Wittekind C (eds). (2002). TNM Classification of Malignant Tumours (6th edn). Wiley-Liss: New York.

Stamos, M.J. \& Murrell, Z. (2007). Management of early rectal T1 and T2 cancers. Clin Cancer Res, Vol.15, No.13, (November 2007), pp.6885s-6889s.

Sun Myint, A.; Griev, R.J.; McDonald, A.C.; Levine, E.L.; Ramani, S.; Perkins, K.; Wong, H.; Makin, C.A. \& Hershman, M.J. (2007). Combined modality treatment of early rectal cancer: the UK experience. Clin Oncol (R Coll Radiol), Vol.19, No.9, pp.674-681.

Taylor, R.H.; Hay, J.H. \& Larsson, S.N. (1998). Transanal local excision of selected low rectal cancers. Am J Surg, Vol.175, pp. 360-363.

UK Cancer Research. http://infocancerresearchukorg/cancerstats/types/bowel/.

Winde, G.; Nottberg, H.; Keller, R. \& et al. (1996). Surgical cure for early rectal carcinomas (T1). Transanal endoscopic microsurgery vs. anterior resection. Dis Colon Rectum, Vol.39, pp.969-976.

Yu, H.H.; Liu, B.; Xia, L.J.; Liu, A.W.; Yang,M.Y. \& Li, K. (2011). Outcomes after transanal endoscopic microsurgery for early rectal cancer and risk factors associated with recurrence. Zhonghua Wei Chang Wai Ke Za Zhi, Vol.14, No.1, pp. 37-39.

Zlobec, I.; Baker, K.\& Terracciano, L. \& et al. (2008). Two-marker protein profile predicts poor prognosis in patients with early rectal cancer. British J Canc, Vol.99, pp.17121717. 
Zorcolo, L.; Fantola, G.; Cabras, F. \& et al. (2009). Preoperative staging of patients with rectal tumours suitable for transanal endoscopic microsurgery (TEM): comparison of endorectal ultrasound and histopathologic findings. Surg Endosc, Vol.23, pp.13841389. 


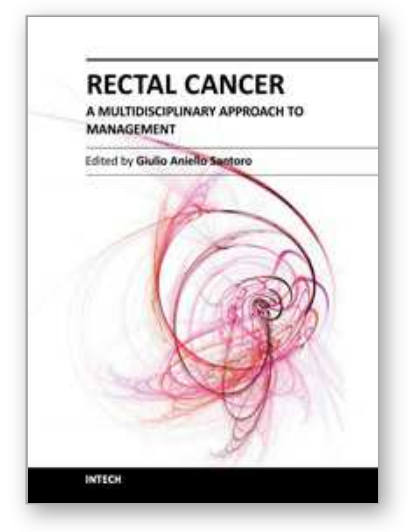

\author{
Rectal Cancer - A Multidisciplinary Approach to Management \\ Edited by Dr. Giulio A. Santoro
}

ISBN 978-953-307-758-1

Hard cover, 410 pages

Publisher InTech

Published online 10, October, 2011

Published in print edition October, 2011

Dramatic improvements in medicine over the last few years have resulted in more reliable and accessible diagnostics and treatment of rectal cancer. Given the complex physiopathology of this tumor, the approach should not be limited to a single specialty but should involve a number of specialties (surgery,

gastroenterology, radiology, biology, oncology, radiotherapy, nuclear medicine, physiotherapy) in an integrated fashion. The subtitle of this book "A Multidisciplinary Approach to Management" encompasses this concept. We have endeavored, with the help of an international group of contributors, to provide an up-to-date and authoritative account of the management of rectal tumor.

\title{
How to reference
}

In order to correctly reference this scholarly work, feel free to copy and paste the following:

S. H. Kho, S. P. Govilkar, A. S. Myint and M. J. Hershman (2011). Rectal Carcinoma: Multi-Modality Approach in Curative Local Treatment of Early Rectal Carcinoma, Rectal Cancer - A Multidisciplinary Approach to Management, Dr. Giulio A. Santoro (Ed.), ISBN: 978-953-307-758-1, InTech, Available from: http://www.intechopen.com/books/rectal-cancer-a-multidisciplinary-approach-to-management/rectalcarcinoma-multi-modality-approach-in-curative-local-treatment-of-early-rectal-carcinoma

\section{INTECH}

open science | open minds

\section{InTech Europe}

University Campus STeP Ri

Slavka Krautzeka 83/A

51000 Rijeka, Croatia

Phone: +385 (51) 770447

Fax: +385 (51) 686166

www.intechopen.com

\section{InTech China}

Unit 405, Office Block, Hotel Equatorial Shanghai

No.65, Yan An Road (West), Shanghai, 200040, China

中国上海市延安西路65号上海国际贵都大饭店办公楼 405 单元

Phone: +86-21-62489820

Fax: +86-21-62489821 
(C) 2011 The Author(s). Licensee IntechOpen. This is an open access article distributed under the terms of the Creative Commons Attribution 3.0 License, which permits unrestricted use, distribution, and reproduction in any medium, provided the original work is properly cited. 